\title{
ABUSIVE TRADE PRACTICES: AN ECONOMIC ANALYSIS
}

\author{
Lester G. TeLser*
}

\section{INTRODUCTION}

Experience guides the development of business practices, and these practices in turn challenge economic analysis. In some cases the analytical challenge has been successfully met and economic science enriched. But economics has not yet attained perfection. Nevertheless, antitrust policy should depend on economic analysis if its purpose is to serve the ends of individual liberty and economic efficiency. To ignore economics leads to restrictions on commerce which can defeat the ultimate purposes of trade regulation despite good intentions. Even in furthering the political purposes of antitrust policy, such as the preservation of small firms, economic science is a helpful guide.

Few trade practices are abusive under all circumstances. Sometimes a given practice is not only compatible with competition but may actually enhance it. Under different circumstances, the same practice may be a symptom of monopoly power without being a source of that power. For example, a particular device may be a vehicle of price discrimination that more fully exploits an already existing monopoly. These are the problems that form the subject of the first part of this paper.

The second part of the paper deals with predatory tactics. Pushed to their extreme, these are tactics designed to destroy competitors; selling below cost is the leading instance of such predatory conduct. To study such economic warfare, it is necessary to consider the relative profitability of tacit collusion, cartel, and monopoly achieved by merger. Absent legal constraints, merger is generally the most efficient route to monopoly profit. These problems lead to the analysis of the forces underlying competition and of the role of antitrust policy in the third section of the paper.

Since barriers to merger play a particularly important role in preserving competition, the fourth part of the article considers the effects on competition of those conglomerate firms that may owe their existence in large part to merger. In general, this discussion poses the questions of why certain firms engage in diverse activities and whether, if large size results, monopoly power becomes a possible consequence.

* A.B. I951, Roosevelt University; A.M. I953, Ph.D. r956, University of Chicago. Professor of Economics, University of Chicago. Contributor of articles to journals in the field of economics and related areas.

The leadership of Professor Aaron Director has stimulated an active oral tradition at the University of Chicago toward applying economic analysis to antitrust problems. I owe a great deal to the many stimulating discussions of these problems I have enjoyed with him. I also wish to thank Professor David I. Fand of the University of Buffalo, Professor Edward Zaibel of the University of Rochester, and Professors Zvi Griliches and George J. Stigler of the University of Chicago for helpful comments. However, I assume sole responsibility for the views expressed herein. 
Abusive Practices: Expression or Source of Monopoly?

In economic theory, a firm possesses a monopoly if two conditions are present: First, changes in the quantity that the firm offers for sale exert a perceptible effect on the price of what it sells. Second, changes in the firm's price, which generally result from a desire to alter its rate of sales, have no perceptible effect on either the price or the amount sold of any other firm. Propositions about the effects of market structure, the relative size of firms, and the number of firms are derived as implications of these two conditions.

The first condition is often the result of a firm's being large relative to the entire market in which it sells its product. The second condition is more complex. It is absent if there are present in the market several relatively large firms of such a size that, while each can perceptibly influence the price by variations in its rate of sales, none has a monopoly and each recognizes its dependence on the policies of its competitors. Perfect competition requires the second condition without the first; thus a firm operates under perfect competition when it can vary its rate of sales without affecting the price of any commodity. When there is the first but not the second condition, there is imperfect competition.

The advantage of stating the concept of monopoly in terms of these two conditions lies in their focus on empirical considerations. Although there are few monopolies in the world, there are many firms that possess a measure of monopoly more or less tempered by the actual or potential availability of substitutes.

Under simple monopoly, the firm charges all customers the same price. For the monopoly to be worth anything, the firm must be able effectively to curtail the supply and thereby to raise the price above cost to the end of obtaining higher profits. The limits of monopoly power are set by the consequences of its exercise. The firm's customers, faced by monopoly prices, can attempt to adapt their needs accordingly and seek substitute products. The monopoly profits will induce the provision of more or less closely competing goods.

\section{A. Price Discrimination}

If a firm can exclude rivals and effectively control the supply of a product, it can generally obtain more profits by discriminating in price among its customers. This may have the effect of increasing the monopolist's output to a level that is closer to what would be produced under a competitive regime. Although price discrimination necessarily entails an average price above the competitive level, it need not require much, if any, reduction of output below the competitive level. Thus, on grounds of over-all allocative efficiency, price discriminating monopoly may be preferable to simple monopoly.

Since it is generally the firm's intention to seek profits and avoid losses and since 
discriminating monopoly is more profitable than simple monopoly, a firm in the possession of monopoly power can be expected to exploit it by price discrimination if possible. Many "abusive" business practices become comprehensible as devices to accomplish price discrimination. ${ }^{1}$

Price discrimination is not always possible. In the first place, the possession of monopoly power is a prerequisite to the practice of price discrimination. Second, it is necessary that there be differences in the intensity of customers' demand for the product. Third, it must be possible to sort out customers according to the intensity of their demand. Finally, price discrimination is effective only if the firm can prevent resales among its customers, for otherwise those who purchase the product at the lower prices might become a source of supply to those who would have to pay the higher prices.

\section{B. Tying Arrangements}

Price discrimination is not always easily recognized. For example, it is present in some tie-in sales, of which the former IBM practice has become the classic instance. ${ }^{2}$ IBM had a monopoly on certain kinds of tabulating equipment, and it required its customers to purchase all of their tabulating cards (on which it held no monopoly) from itself. Some would interpret this as IBM's attempt to extend its monopoly from tabulating equipment to tabulating cards. A more plausible explanation is that the customers' rate of use of the cards measured their rate of use of the equipment. Hence, by charging a price for the cards in excess of their cost, IBM was able to discriminate among its customers according to the intensity of their demand for tabulating equipment. If customers had been allowed to purchase cards from sources other than IBM or from each other, IBM could not as easily have obtained the additional profits of price discrimination.

Not all nor even most tie-in sales necessarily imply the existence of monopoly, let alone price discrimination. Many products are tied together either (I) because such tying lowers costs or (2) because it serves the convenience of customers. Cost savings are made possible by complementarism among the components, either in production, marketing, or other functions. For instance, though men's suits are sold with buttons, there is no reason to suspect price discrimination. Not even the fact that cars are equipped with wheels and tires implies price discrimination despite the doubts of some about the intensity of competition in the automobile industry. These common tie-ins also reflect the factor of customer convenience. In addition, customers may prefer, as a matter of convenience only, to be able to buy several complementary goods or services at one time and place; this preference is illustrated by the existence of various kinds of retail stores.

\footnotetext{
${ }^{1}$ This is a central hypothesis in the classic article on antitrust policy, Director \& Levi, Law and the Future: Trade Regulation, $5 \mathrm{I}$ Nw. U. L. REv. 28I (1956).

${ }^{2}$ International Business Machs. Corp. v. United States, 298 U.S. 131 (x936). This explanation of the IBM practice and the general analysis of tie-in sales and full-line forcing as being in certain instances, methods of price discrimination originated with Professor Director.
} 
More generally, tie-ins do not necessarily imply the absence of marginal cost pricing despite appearances to the contrary if there is competition. Thus most department stores offer "free" delivery whether the article purchased is a box of candy, which the customer himself generally carries out, or a living-room sofa. If there are candy stores nearby that do not deliver and charge lower prices, the department store, to meet their competition, may charge equally low prices in the expectation that few of its customers will demand delivery. Or, if its candy customers require delivery, the price of candy in the department store will exceed the price in the candy store. Customers who do not want delivery can purchase from the candy store and pay a lower price, while those who wish delivery can buy candy in the department store and pay a higher price. Although delivery is tied to the product, competition prevents the emergence of profits due to price discrimination between the two classes of customers.

Subtle but invalid arguments that rely on the composite nature of most commodities are sometimes used to connect price discrimination with tie-ins. Thus a department store carries many goods of which only a limited number appeal to particular classes of customers. The wide selection is, so to speak, tied together under a single roof. It does not follow that this presents the department store with opportunities for discriminating in price between the shoppers who buy only a limited range of goods and those who purchase a wider variety. For example, customers who never buy ribbons or laces do not subsidize those who do buy these items although the prices of all goods may include a contribution to the general overhead, which seemingly enables the provision of a ribbon and lace counter. Price discrimination, if at all possible, would necessitate that prices on most items sold in the department store exceed competitive levels-that is, the prices for the same goods available from other sources of supply, including competing department stores that offer very nearly the same range of goods and services. Despite the fact that, for the sake of convenience, a shopper in the department store may willingly pay a higher price for certain articles to avoid the trouble of patronizing lower-priced sellers located elsewhere, this does not necessarily yield a monopoly profit to the department store. It is a mistake to ignore the cost of providing in one place a large selection of goods which eases the burden of shopping. Convenience is a costly service and will not be offered without charge, albeit an implicit one.

\section{Exclusive Dealing and Full-Line Forcing}

Although exclusive dealing may be a necessary adjunct of a price discrimination scheme, as, for example, in the IBM case, it does not always signify price discrimination or even monopoly. Moreover, a manufacturer does not always advance his interest by requiring his customers to deal exclusively with him, nor is it always true that the distributors, who are the customers of the manufacturer, will always benefit from an exclusive franchise. The manufacturer who requires the exclusive 
custom of the dealers may forego the benefit of keener competition among them and suffer that loss of sales which is a consequence of the higher resale price. Distributors confined to a single line exclusively may sacrifice the patronage of those customers who prefer competing products. Exclusive dealing obviously does not emerge under circumstances where it would cause harm to both of the parties to it. If it does in fact harm one of the parties, then the other, who benefits from its imposition, must have enough monopoly power to require exclusive dealing.

Such exclusive dealing as is present under competition necessarily benefits at least one of the parties without harm to the other. For instance, dealers may prefer to handle the products of a single manufacturer exclusively if they can thereby reduce their costs through holding less inventory. This is true of gasoline stations that handle a single brand of gasoline and thus avoid the expense of more than one or two storage tanks. Gasoline outlets may also prefer to handle one line of batteries and one brand of tires to avoid the expense of duplicate types and sizes, but it does not necessarily follow that the two articles would be of the same brand. Though it can be cheaper to buy both articles from the same concern, there is no reason why this should always be advantageous to the gas stations. There is reason to suspect abusive practice if all of the gasoline stations under the same emblem handle the tires, batteries and accessories of the same firm, as in the Standard Stations case. ${ }^{3}$ This practice may be a vehicle for discriminating in price among the gasoline stations according to the volume of their repair and ancillary business.

The Standard Stations case also illustrates "full-line forcing," the practice by a manufacturer of requiring a dealer to handle his complete line. Some may wish to argue that full-line forcing represents the manufacturer's effort to impede entry if a rival cannot secure dealers without offering them an equally full line. This might have the effect of limiting access to the retail market. In addition, if it requires a larger capital to provide a wider range of products and if the firm faces a rising cost of capital in the financial markets, full-line forcing might allow fewer firms to enter the industry. Even if larger capital requirements are not an insurmountable barrier and merely delay entry without entirely preventing it, the firm able to impose its entire line on its dealers may thereby slow the erosion of its monopoly profits.

Full-line forcing may be sought by a manufacturer innocent of any design to discriminate in price. Suppose there is a publisher of mathematical books of which some are widely used text books and others are abstruse treatises on special topics of interest to a limited market. The mathematics publisher may require bookstores to handle his complete line without exception. Otherwise, the publisher fears, the less popular books would not gain sufficiently wide distribution while the bookstores concentrated only on the more popular texts. The argument relies on the

\footnotetext{
${ }^{8}$ Standard Oil Co. v. United States, 337 U.S. 293 (1949).
} 
effect of display in promoting sales. Thus potential customers may wish to examine the treatises before deciding on purchase, and this is impossible without sufficient display. In addition, the publisher might establish minimum retail prices under these conditions in order to preserve a wide network of outlets. In the absence of resale price maintenance, customers might examine the books in a store with a large inventory and purchase from another without a display which can sell at a lower price. ${ }^{4}$

The practice of block booking in the motion picture industry also illustrates full-line forcing. Under some demand conditions it can be explained as price discrimination. The motion picture distributors in the leading case on the subject ${ }^{5}$ required television stations to accept a complete package of grade A and grade B motion pictures and in effect charged a single price for the package on a take-it-orleave-it basis. Under the appropriate demand conditions, this practice might enable a larger profit than could be obtained by pricing each movie separately and allowing exhibitors to buy any collection of films as they pleased. Some of the complications in deciding between the two alternative pricing schemes are best illustrated by a numerical example. The table shows the prices obtainable for grade $\mathrm{A}$ and $\mathrm{B}$ films in three cities:

$\begin{array}{cccr} & \text { City I } & \text { City 2 } & \text { City 3 } \\ \text { Grade A } & \text { I30 } & \text { I25 } & \text { I70 } \\ \text { Grade B } & \text { I0 } & \frac{55}{180} & \frac{5}{I 75} \\ \text { Sum } & \text { I40 } & \text { I80 }\end{array}$

In all three cities, exhibitors are willing to pay more for grade A than for grade B movies. Moreover, there is an inverse relation between the value of the two types of movies so that grade $\mathrm{B}$ movies are most valuable where grade $\mathrm{A}$ movies are valued less and vice versa. If the motion picture distributors were to charge the highest single price for each movie that would induce exhibition in all three cities, the price of $A$ would be 125 and the price of $B$ would be 5. This yields a total revenue of 390. However, under block booking the package could be sold for 140 in all three cities since this is the lowest price of the combination. Therefore, the receipts under block booking would be 420 , which exceeds the single pricing revenue. Still more profitable would be the policy of setting a price of 55 for the grade $B$ movies and 125 for the grade A movies. This would give the distributor 430, although grade B movies would not be shown in either City I or City 3 .

It takes a somewhat complicated mathematical analysis to state precisely the conditions that would make block booking more profitable than single pricing. Roughly speaking, block booking is more profitable if the variation of the revenue for the combination among the cities is not too large. For single pricing to be more profitable than block booking it is necessary that not all films be shown in

\footnotetext{
'See also Telser, Why Should Manufacturers Want Fair Trade?, 3 J. LAw \& Econ. 86 (1960).

${ }^{6}$ United States v. Loew's, Inc., 37 I U.S. 38 (1962).
} 
all markets. It should be added that if there were not an inverse relation between the valuation of the two kinds of movies, it would generally be true that single pricing is more profitable. The analysis for three or more different classes of films is somewhat complicated by combinatorial aspects but offers no fundamentally new difficulties. The practice of block booking is a fascinating example of an intricate pricing problem that deserves both theoretical and empirical study.

\section{II}

\section{Sales Below Costs and Economic Warfare}

The business practices thus far analyzed, in so far as they have anything at all to do with monopoly, are more often its expression than its cause. There are other business practices often deemed to be predatory and aimed at lessening competition. If monopoly yields profits in excess of competition and business firms strive for profits, then the desire for profits may be transmuted into a propensity to monopolize. Sales below costs are interpreted as a means of destroying rivals for the purpose of seizing monopoly power. The analysis of these aspects of competition becomes riddled with the metaphors of warfare, and the law is seen as the bulwark against cutthroat competition. Size itself is always considered advantageous, and new entities-conglomerate firms-arise and are said to harm competition. In this area conventional economic analysis is claimed to falter, and the constant demand for new theories brings forth a supply of old fallacies in a new dress. ${ }^{0}$

For the multi-product firm that operates in an uncertain world having an indefinite horizon, primitive economics does not suffice to reckon costs. A profitmaximizing firm may sell an article at a price below its out-of-pocket expense for the same reasons that impel it to build a plant before having sold the output that the plant will produce. Just as the latter is investment, so is the former. A firm attracts new customers by giving them free samples hoping to secure their longterm patronage. This is a kind of investment analogous to advertising and every bit as rational as expenditures on tangible capital assets. Clearly these are not abusive business practices. Indeed, to prevent a firm from marketing a new product or attracting new customers to an old product by offering especially low prices might protect an established monopoly from new competition.

A multi-product firm that seeks maximum profit does not always serve its interests best by pricing each article so as to account for its direct costs only while ignoring indirect repercussions on total cost or revenue. For instance, a firm that sells a variety of products in a consumer market needs to inform customers of its prices. Although customers shop in order to learn prices, it is often in the seller's

\footnotetext{
' For a convenient and succinct summary of these doctrines by one of their leading proponents, see the statement of Corwin D. Edwards in Hearings Before the Subcommittee of the Senate Committec on the Judiciary on Economic Concentration, Part 1, Overall and Conglomerate Aspects, 88th Cong., 2d Sess. 36-47 (1964).
} 
interest to lower shopping costs in various ways. However, it may be unduly expensive for the firm to provide potential customers with a price catalogue if it sells goods that frequently change in price. Instead the seller may prefer to feature the prices of a small sample of goods selected to signal potential buyers as to its competitiveness. The choice of goods placed on sale is governed by their familiarity to buyers, the ease of judging the quality of the goods, and the importance of the goods to the customers. The last point ensures that buyers are likely to note and remember the prices of the goods placed on sale, and the first two serve to allay the possible impression that the low prices are made possible by a sacrifice of the quality of the goods. Thus, by offering bargains, the seller hopes to increase sales. The cost of the sale is analogous to an investment upon which the firm seeks its usual rate of return.

In a different category are those instances in which it is alleged that the firm attempts to drive out competition by selling products below cost so as to inflict at least equal losses per unit of sales on its rivals. In this case, victory-i.e., monopolyis the reward to the firm with the longest purse. Some historians have claimed that in the original Standard Oil case ${ }^{7}$ Standard's low prices in certain local markets caused it to suffer losses and were designed to inflict similar losses on competing refiners and ultimately to drive them out of business. Similarly, it is claimed that the original tobacco trust used "fighting brands" to destroy competition. There are many other popular examples. . $^{8}$

To clarify the issues it helps to suppose that firms are legally free to pursue monopoly profits as they please. By posing this hypothetical problem, it is possible to study what firms would prefer to do if they were unhindered by antitrust enforcement, and the role of the law may therefore become visible. Therefore, let us suppose that firms are free to ruin competitors by the use of predatory tactics, collude with rivals by forming a cartel, or combine by merger into a monopoly.

It is unclear why business men who are interested in maximum profit would engage in economic warfare as a means to monopoly. Such warfare is always less profitable to the victor than a settlement between the contending parties reached in the beginning. The aggressor firm must acquire its competitors' assets for it cannot literally destroy them by economic warfare. If it tries this course, it will find itself engaged in an endless, profitless venture. No matter what is the result of a price war, if the same outcome-a monopoly-is attainable without warfare, then all parties would benefit by avoiding conflict. They could prevent the losses of the price war itself, and, if the end result is monopoly, the additional profits would be received without the delay of an intervening period of warfare. Either some form of collusion or a merger of the competitors would seem preferable to any possible outcome of economic predation. By merger or collusion a group of competing firms could

${ }^{7}$ Standard Oil Co. v. United States, 22 I U.S. I (I9II).

${ }^{8}$ See E. A. G. Robinson, Monopoly (194I). 
pursue a well-meshed strategy that would secure for them the joint profit maximum. The only source of conflict would arise in the imputation of the profit. If the firms are sufficiently intelligent to recognize the joint benefit of monopoly or even if merely one firm has this insight, then either the group should be able to reach a compromise governing the allocation of the joint profit maximum or the one firm that sees the potential monopoly profit could acquire its rivals by paying an amount in excess of the present value of the competitive profits; in the latter event, the sacrifice of a large fraction of the monopoly revenue could be acceptable to the acquiring firm without damage to the interests of its owners. One scholar who examined the Standard Oil record found no evidence of economic warfare, although there was considerable evidence that Standard bought rivals for a good price and thereupon scrapped the acquired capacity. ${ }^{9}$

The flaw in the arguments rationalizing price warfare presents itself in another guise in discussions of cartels. A cartel generally fixes a price above the competitive level and provides for a system of sales quotas. Many would argue that cartels are fragile even if entry can be prevented because they present the cartel members with the irresistible temptation to pursue self interest at the expense of the collective good. Thus it is claimed that a cartel member is likely to attempt to increase its share of the profit above the amount agreed upon implicitly by the assignment of quotas. This happens when the cartellist shades his price somewhat below the cartel level and thereby increases his sales. If all cartellists are equally avaricious and myopic, then what is a temptation for one will be equally inviting for all. Hence, prices will eventually be reduced to competitive levels, and the cartel will be finished. This analysis requires the cartellists to be sufficiently rational to establish a quasi-monopoly at the outset but insufficiently cooperative to maintain it in the long run because each is willing to sacrifice its share of the monopoly profit for the sake of a temporary gain. The element of irrationality this admits into the cartellists' conduct resembles that implicit in the behavior of firms that engage in price warfare in order to determine which survivor is to be left with a monopoly. In either case, some form of cooperation is more profitable than rivalry, and it is more reasonable to except the farsighted firms to acquire the uncooperative ones by outright purchase rather than suffer the losses of price warfare or the destruction of the cartel.

\section{III}

\section{Competitron and the Role of Antitrust Policy}

Thus far the discussion deliberately ignores the role of the antitrust laws for the sake of analyzing the form that competition might be expected to take in the absence of legal constraints. At this stage, it appears that rationality on the part of firms dictates either cooperation via cartel or monopoly via merger, since both are

\footnotetext{
${ }^{9}$ MeGee, Predatory Price Cutting: The Standard Oil (N.J.) Case, I J. Law \& Econ. 137 (1958).
} 
superior to predatory tactics. Does it follow that but for legal hindrance there would be monopoly in every industry?

The vigor of competition in an industry generally rests on two sustaining factors, ease of entry and the small size of the efficient firm relative to the total market. Thus there is vigorous competition in agriculture and many of the service industries; apparently these businesses require the close attention of the owner because the delegation of responsibility to a hierarchy of hired managers is too costly. In the recent past, similar conditions seemed to prevail in retailing, but the development of retail chains implies that with proper organization and control a larger size of firm becomes efficient. In general, if there are diseconomies of scale, then not only would a single firm in the industry be unprofitable but also a cartel could not operate efficiently because its governing board would be subject to at least the same disadvantages that would affect a monopoly.

Some manufacturing industries seem to resemble agriculture and the service industries in that entry is frequent and small firms predominate. However, there is scant empirical evidence of an upper limit on the efficient size of enterprise in many manufacturing industries. Despite a large expansion of the economy and of these industries during the past twenty-five years and possibly for a longer period, concentration levels, i.e., the combined market share of the four leading firms by industry, remain stable. This is a very important finding. It means that as markets grow and despite the tendency for this growth to reduce concentration, the bigger firms are on the whole able to keep pace and thus that there cannot be net disadvantages to large size. ${ }^{10}$ These findings do not necessarily imply that the same four firms remain the leaders, nor do they imply that the largest size is necessarily the most efficient, though this may be true of a few industries. In many industries, there is a fairly wide dispersion of firm size without a marked tendency for one range of size to become the mode. ${ }^{11}$ This evidence is consistent with the view that over a substantial range of size there are approximately constant returns to scale.

As noted above, one of the pillars sustaining competition is the existence of a maximum limit on the efficient size of enterprise, so that, as markets grow, cost conditions dictate a growth in the number of firms in the industry and a decline in concentration; the evidence of manufacturing gives little reason to suppose that this is an important support of competition in most industries. The other pillar of competition is the possibility of entry or the provison of close substitutes. Here, too, the available evidence on entry gives only a little comfort. Entry does occur on a large scale in some industries, and the result is low concentration levels, large

\footnotetext{
${ }^{10}$ See generally Ralph L. Netson, Concentration in the Manufacturing INDUStries of the UnIted States: A Midcentury Report ( 1963 ). Nelson shows an inverse relation between expansion of markets and changes in concentration.

${ }^{12}$ See Stigler, The Economies of Scale, I J. LAw \& Econ. 54 (1958).
} 
numbers of competitors, and presumably active competition. However, there are many industries in which, despite high profits and growth rates, entry has been infrequent or unsuccessful. Such entry as occurs tends to promote competition, but it does not appear as an important factor in many industries. ${ }^{12}$

The inescapable conclusion is that the antitrust laws vigorously enforced play an important role in maintaining competition. Moreover, the prohibitions on merger are particularly important. To understand why this is so, it is necessary to study the disadvantages of cartel or collusion as against the advantages of merger of competing firms. First, it is clear that the formal organization of a cartel is able to secure profits at least as well as tacit collusion among a group of firms. However, a cartel cannot obtain as large a total profit as a single firm created by the merger of the cartellists even where the returns to scale are constant or decreasing. The reasons are inherent in the cartel's form of organization. In a cartel there is, in essence, government by committee. The representatives of the sovereign firms that comprise the cartel are the members of the governing committee. Since the firms retain their separate identities and since there are always fresh sources of disagreement over the proper course of cartel strategy, there is an ever present danger of secession, which might result in the formation of one or more new cartels in competition with each other and with the remains of the original one. A single firm that buys out the cartellists and thus becomes a monopoly can avoid these problems.

Moreover, even if there are decreasing returns to scale, they must work at least as strongly to the detriment of the cartel as to the company formed out of the merger of the cartellists. Whatever are the sources of the diseconomies that impede the operations of a single firm under the direction of a single chief executive, they will operate with at least equal force against the governing body of the cartel. If there are any benefits from the decentralized control of the cartel, these benefits will also be within the reach of the single firm.

Since a firm is not a nation and is certainly not a republic, it seeks maximum profits for its owners and not liberty for its constituents. Divided authority in a cartel may preserve the liberty of the members but only at the expense of efficiency. Therefore, in so far as a cartel resembles a republic it suffers disadvantages that reduce the profits to the owners of the cartellists. A single firm under the control of a responsible chief executive can, in principle, single-mindedly pursue profits. The greater profitability of a monopoly thus implies that, in the absence of legal barriers, cartels would coalesce into monopoly.

For these reasons, the legal constraints on merger assume a special importance because, according to the preceding analysis, merger is the most efficient route to monopoly. It should hardly be necessary to add that monopoly is not necessarily

\footnotetext{
${ }^{12}$ See John Fause, New Firm Entry in Manufacturing Industrics (unpublished thesis in University of Chicago Library, 1962).
} 
the purpose of merger and, indeed, that mergers will enhance competition under some conditions.

Colluding firms cannot generally obtain as much profit as would be possible in a cartel, and the latter organizational device is, in turn, normally inferior to merger. Nevertheless, tacit collusion may not be uncommon. Though the law may prevent cartels and mergers with intent to monopolize, it cannot compel competition. $^{13}$ If there is no overt conspiracy but merely an understanding among the firms, it is still possible for the firms to secure some of the benefits of monopoly. Even if the law did not prevent the use of certain tactics that are considered abusive but that may in fact be beneficially competitive in some contexts, competition might still falter so long as there is no remedy for tacit collusion. Paradoxically, the gains from tacit collusion reduce the incentive to engage in such abusive practices, and competition may become so "fair" as to verge on monopoly. Obviously, there are circumstances under which price cuts may advance the interests of tacitly cooperating firms. However, some price cutting might be motivated by a desire to punish an overly greedy competitor, and the law may succeed in reducing the incidence of such tactics and thereby weaken the forces of collusion.

IV

\section{Conglomerate Firms}

\section{A. The Procter \& Gamble-Clorox Case}

Although size itself is no offense, it is hard to explain some recent decisions on any other ground. Perhaps the best example is the decision reached by the Federal Trade Commission in the case arising out of the acquisition of Clorox Chemical Co. by Procter \& Gamble Co. ${ }^{14}$ This case represents a victory for the doctrine of the conglomerate firm, which therefore merits close attention. Its proponents claim that by sheer size and diverse pursuits, the conglomerate firm can seize competitive advantages so effectively as to diminish competition. ${ }^{15}$ Since the conglomerate firm grows neither vertically nor horizontally but merely embarks on new lines of business, it is difficult to understand how competition is harmed. On the contrary, it would appear at first blush that conglomerateness enhances competition. It is best to begin with an analysis of some of the issues raised in the Clorox case.

Clorox is the leading firm in the household liquid bleach market, and, at the time of its acquisition by Procter \& Gamble, its market share was approaching fifty per cent. Its closest competitor was Purex with a market share of sixteen per cent, and the next three firms together accounted for about thirteen per cent of the market. It is important to note that Clorox attained its large relative size while

\footnotetext{
12 Director \& Levi, supra note $\mathrm{I}$, at 287 .

16 Procter \& Gamble Co., 3 Trade REg. Rep. I 16673 (FTC 1963).

${ }^{15}$ Statement of Corwin D. Edwards in Hearings, supra note 6 , at 37 .
} 
unconnected with any giant enterprise. However, Procter \& Gamble's financial and economic strength were supposedly capable of increasing the market share of Clorox and of thereby diminishing still further the state of competition in the industry.

One of the benefits from the merger was claimed to be a saving in the amount of Clorox's advertising outlay because large advertisers are able to obtain quantity discounts from advertising media. It was estimated that Clorox saved $\$ 138,500$ in one year on its advertising because of its Procter \& Gamble connection. Since there are no figures available giving the total advertising expenditure by Clorox, it is impossible to know how important a saving this was. Perhaps the savings amounted to as much as ten per cent of Clorox's total advertising expense. However, regardless of the importance of the savings, it is instructive to analyze the economic consequences and causes of the advertising economies because the same general kind of analysis applies to other hypothetical advantages of a conglomerate merger, though the particular detail would vary from one benefit to another. ${ }^{16}$

Assuming there are advertising savings, other concerns which advertise on a large scale would also find it advantageous to enter the household bleach market by purchasing the competitors of Clorox, thereby obtaining comparable advertising economies and the consequent cost reduction; indeed, the availability of advertising economies may partially explain the emergence of large conglomerate firms in consumer product industries generally. If there is enough competition among these large firms, consumers would benefit to the extent that prices are driven down as a result of the lowering of costs.

If one objects to the acquisition of an established brand by Procter \& Gamble, then, on similar logic, one would also have to object to its entry into the bleach business through the introduction of a new brand. In either case, the advertising savings confer an advantage on Procter \& Gamble, and the argument advanced against the merger would also support the conclusion that a new brand sponsored by Procter \& Gamble would enjoy such an advantage that it could weaken competition eventually. The only difference is that it would take Procter \& Gamble a longer time to establish the new brand.

Perhaps the objection to the acquisition arises not only from the possible advertising economies but also from the leading position of Clorox. Had Procter \& Gamble acquired Purex, the second leading brand, or some other smaller established brand it might have gained the advantage of promoting an established brand without running afoul of the law. The only difference between the economic effect of entry of a new brand and the purchase of a small established brand is most likely to be the longer time it would take to build up a new entrant's share.

\footnotetext{
${ }^{10}$ Though not an issue in the case, one may argue that the advertising itself is a source of monopoly. Hence, Clorox may owe its large relative size to its advertising outlay. For an analysis of this problem, see Telser, Advertising and Competition, 72 J. PoL. Econ. 537 (1964).
} 


\section{B. Advertising Economies and Conglomeration}

It is important to analyze the circumstances that permit savings from large scale advertising. These savings may result from forces inherent in the technology of the advertising industry or may reflect certain monopoloid elements in the market for advertising services. In either case, if there is competition among the advertisers, the final consumers of their products stand to gain.

Even in a competitive market for advertising services there can be quantity discounts. If the marginal cost of advertising falls with volume, competition among the various firms engaged in the business of providing advertising services would create a rate schedule providing for quantity discounts. In television, for example, although a network program is more costly than a local program, a temporary combination of local programs to cover the same population as a single network program may not only be more expensive but also may fail to attract as large an audience because network programs are generally more popular. Moreover, those local programs able to attract a relatively large audience locally can often do so nationally as well. As a result, there is a tendency for the more successful local programs to become offered nationally. Hence, a large advertiser that sells a conglomerate of consumer goods will find national advertising advantageous; such a firm can get lower advertising rates than a smaller concern that specializes in fewer products. The advertising rate structure of magazines and newspapers is the same as in television and radio because of the nature of production techniques. Formally, advertising costs rise with audience size but not as rapidly. This confers economies that tend to increase the efficient size of enterprise on readily comprehensible and conventional economic grounds.

Large advertisers may have monopsonistic power because of their large advertising outlays relative to total expenditures on advertising. Thus the ten leading advertisers on network television account for about thirty per cent of the total receipts of this medium. In most of the other advertising media, the largest advertisers are of approximately the same relative size. In newspapers the advertisers of largest size are generally department stores and food chains, whereas in the national media they are large manufacturers of consumer goods. Even if there were competition among the firms in the advertising industry, the relatively large size of the buyers with respect to the total market for advertising services could explain their monopsonistic power and their ability to obtain lower advertising rates. ${ }^{17}$

The analysis becomes complicated by the possibility of monopolistic elements on the seller side of the advertising industry. There are only three television networks and only a few television stations in most localities. In addition, there are relatively

\footnotetext{
${ }^{17}$ See JoAn RoBinson, THE Economics of IMPERfECt COMpetrtion (1933). Book VI contains the pioneering and best analysis of monopsony.
} 
few newspapers in many cities. This suggests the possibility of monopolistic power on the sellers' side confronting the monopsonistic power of the relatively large buyers. This market situation-bilateral monopoly-has no clear-cut analysis, and the most that can be said is that the price will settle between certain ill-defined limits while the quantity will be less than the competitive amount. It is reasonable to expect the small advertisers to pay higher rates than the large ones under these market conditions.

Nevertheless, given sufficient competition in the markets in which the advertisers sell their wares, consumers can benefit to the extent that the competition among the sellers in these markets results in lower prices made possible by the cost savings on advertising. Because few single product markets would be large enough to afford these economies, few advertisers other than conglomerate firms can attain sufficient size to realize the advertising savings. The final effect of the growth of conglomerates might be lower prices to consumers, and this could be considered an enhancement and not an impairment of competition.

\section{Specialization Versus Conglomeration}

By specialization, it may be possible for a firm to benefit from scale economies without being large itself. Small firms collectively may provide a large enough market for more specialized firms to cater to their needs. Since different activities frequently require operation on different scales for optimal results, specialization makes it possible to combine such activities through the market in such a way that the gains from the large-scale performance of some operations are attainable without necessarily entailing the expense of inefficient large-scale performance of others.

An illuminating example is in risk bearing. Suppose there is an industry which contains such a large number of firms that the earnings of each is subject to independent random variation. If these companies merged, it would be possible to reduce the variance of the combined earnings stream. This would lower the cost of capital to the enterprise formed by the merger. However, the nature of the business may make large size uneconomic. Therefore, the expected earnings of the combination is less than the sum of the expected earnings of the separate firms. Thus, while the insurance principle confers an advantage on merger because of the reduction of the variance of the earnings stream by the pooling of risks, other considerations impose disadvantages of large scale that may more than offset these savings. Specialization solves the problem. Each of the firms could obtain funds individually from investors or lenders who diversified their portfolios at the same cost that a conglomerate firm would bear. In other words, if investors invested appropriate amounts in the various firms in the industry, they could obtain a combined earnings stream with as low a variance as the merged firm, and the sum of the expected earnings would exceed that of the merged firm. Similarly, lenders who diversified 
their loans would reduce the allowance for risk in the interest charged. Competition among investors and lenders would drive the cost of capital down to a level consistent with the variance of the combined earnings stream. Therefore, those firms and individuals that specialize in providing capital funds can secure the advantages of diversification without themselves engaging in the actual production or sale of the products.

No one can predict the outcome of certain kinds of research. Firms are willing to invest in these uncertain pursuits because of their profitability on average. ${ }^{18}$ The insurance principle operates here, and it might be thought that a large enterprise is most capable of research because its conglomerate lines of endeavor enable it to pool risks. It may be that some conglomerate companies owe their nature to the pursuit of far ranging researches some of which turned out successfully. As a result, the firm, to its own surprise, may have found itself in a new industry. It was a mechanical engineer at General Motors Corp. who developed Freon, which became the basis for the entry of General Motors into refrigerator manufacture.

Research does not necessarily impel firms to bigness. Specialization may. allow relatively small firms to engage in research without having their own laboratory. They can hire the services of specialized research firms on contractual arrangements made possible by the laws of large numbers.

Still another example of specialization is in marketing. Suppose a firm manufactures a rather specialized article, such as a certain type of transistor. Its. market consists of those firms that manufacture electronic gear using the particular transistor. The firm may contemplate hiring salesmen who would call on electronics manufacturers and offer for sale its limited line of transistors. Since this would obviously be wasteful, it may be thought that the transistor firm has recourse only to such expansion of its product line as would enable it to occupy its sales staff fully. Though this explains the diversity of some firms, it is not the only avenue to full utilization of capacity. Specialized firms that handle the products of several small manufacturers can accommodate the transistor firm. These specialists, jobbers or industrial representatives, can fully utilize a sales staff by handling the accounts of a number of specialized producers.

\section{Conclusions on Conglomerate Firms}

Firms engage in diverse activities if they think they will be profitable. To a casual observer without access to the same detailed information as is available to the company, the reasons may be wanting. Nevertheless, there are often good reasons for conglomeration, and these reasons need not be sinister in any way. The examples cited above are illustrations of some of the innocent reasons.

Granting that there are unobjectionable reasons for mergers, there is still the

\footnotetext{
${ }^{18}$ See generally John Jewres, David Sawers \& Richard StmLierman, The Sources of Invention (1958).
} 
question of how often there occurs a merger of firms in different industries that lowers costs and simultaneously diminishes competition in one of the industries. For instance, suppose a merger would reduce expenses because of technical complementarism between the two firms even though they are in separate industries. The lowering of costs enables a price reduction that permits the firm to increase its market share in one or both industries. Moreover, the firm may increase its profits because of the competitive advantage created by the merger. However, unless the source of the efficiency is unique and therefore unattainable by any other pair of firms in the two industries or unless there are so few firms in the two industries to begin with that only a few could take advantage of the technical complementar. ism, further conglomerate mergers would occur and competition would survive. If there are enough firms in a position to lower costs by merger, competition among them will result in savings to the consumers. Thus, the hypothetical merger might lessen competition only if one of the industries was highly concentrated to begin with or if for some other reason only a few firms were able to secure the cost reduction through an increase in technical efficiency. Whether this concatenation of circumstances is sufficiently common to cause concern seems doubtful.

Conglomeration in itself does not confer monopoly power, nor is large size necessarily a source of economic power. Corporate syndicalism can endanger democracy, but there is yet to appear an argument that relates monopoly power to absolute size. The conventional wisdom of economics finds monopoly only in a firm that is large relative to a market appropriately measured. Similarly, there is monopsonistic power only in the hands of a buyer that is large relative to the pertinent market.

\section{Conclusions}

It is now convenient to summarize the arguments presented here. First, many business practices that apparently arise in monopolistic settings are also to be found in competitive industries. Blanket prohibitions against such practices might harm competition more than would monopoly. In so far as these practices do arise in conjunction with monopoly, they are more often its expression than its source. Firms with a measure of monopoly power seek to exploit it as much as possible and frequently contrive methods of price discrimination to this end. The more successful the price discrimination, the greater is the incentive toward increased output. The final result of effective price discrimination might be a total output that falls not far short of the competitive level. Thus monopoly that cannot discriminate may lead to a more serious misallocation of economic resources than one that can.

Discriminatory practices are often mistaken for predatory tactics. It is doubtful whether predatory tactics are a frequent means to monopoly because of their unprofitability relative to the alternatives, of which the most readily available is 
probably tacit collusion in its more clever guises. Since the law cannot compel competition, ingenious cooperation emerges where possible. Such collusion is normally less profitable to the participants than either a cartel or a monopoly achieved through merger would be, yet it is likely to be more common as more effective antitrust enforcement impedes cartels and monopolistic mergers. Barriers to merger and cartel are undoubtedly the most powerful expression of public policy toward the preservation of competition. 